\title{
Enzyme purification with aqueous two-phase systems: comparison between systems composed of pure polymers and systems composed of crude polymers
}

\author{
Armando Venâncio, Catarina Almeida, José A. Teixeira* \\ Centro de Engenharia Biológica, Universidade do Minho, Largo do Paço, 4709 Braga codex, Portugal
}

\begin{abstract}
The main drawback when using aqueous two-phase systems for macromolecule purification is the high cost of most polymers used. The purification of an enzyme, alcohol dehydrogenase, from a crude extract of Saccharomyces cerevisiae was tested in systems composed of poly(ethylene glycol) and a crude hydroxypropyl starch or Reppal PES 100, a purified fraction of hydroxypropyl starch. Purification factors measured for the enzyme were very similar in both systems (between 0.8 and 1.4 for both systems in the upper phase). However, systems composed of Reppal PES present a greater recovery of enzyme, between $77 \%$ and $100 \%$ versus $60 \%$ and $100 \%$, while systems composed of crude hydroxypropyl starch exhibit a larger $\Delta \log K$ for the tested ligand, 1.26 versus 0.81 .
\end{abstract}

Keywords: Enzyme; Alcohol dehydrogenase; Polymer

\section{Introduction}

Aqueous two-phase systems (ATPS) provide benign and non-destructive environments for bioseparation processes. These phase systems are attractive in that they provide a mean of separation which is easy to manipulate, reliable in scaling-up, simple and effective in operation [1].

A very difficult mechanical separation step can be replaced by an extraction process which allows the separation of cells and cell debris from a soluble protein by partition into opposite phases. Besides physical extraction, a reactive extraction may be applied. This is accomplished by confining a ligand into one phase by covalent binding to one of the polymers forming the system, usually poly(ethylene

${ }^{*}$ Corresponding author. glycol) (PEG). It is also possible to bind the ligand to a third polymer, that preferentially favours one of the phases and has the advantage of being precipitated by a change in $\mathrm{pH}$, temperature or other. ATPS have been used for enzyme purification in large-scale $[2,3]$, affinity precipitation [4], affinity purification [5] and extractive bioconversions [6].

Thus far, most of the laboratory work has been done with a system composed of fractionated dextran and PEG. The properties of this system are well studied but, despite the ease of scale-up, the high cost of fractionated dextran prevents the use of this system on large-scale processes [7].

As an alternative, for large-scale enzyme processing, the PEG-salt systems have been used [8]. Although inexpensive, the high salt concentration in both phases of this system limits its usefulness. PEG-salt phase forms only at rather high ionic 
strength, which may cause the denaturation of sensitive biological structures and the dissociation of most ligand-protein complexes [9]. Another problem related to the use of PEG-salt systems is waste disposal. ATPS based on dextran, starch derivatives and cellulose derivatives have the advantage of being biodegradable [10].

As a consequence, there is a need to develop new ATPS suitable for large-scale processes. By allowing processes to be carried out at low salt concentrations, polymer-polymer systems may be more useful than PEG-salt systems. Since polymers and salts used to generate two-phase systems alone can account for as much as $75 \%$ of the total production cost of an aqueous phase extraction [11], it is necessary to find inexpensive substitutes for fractionated dextran with equivalent partition properties.

Several polymers, such as crude unfractionated dextran [12], starch derivatives [13,14], poly(viny] alcohol) [15], maltodextrin [16], cellulose derivatives [17], poly(ethyleneimine) [18] and agarose [19] have already been tested. The utilization of polysaccharides and its derivatives used in the paper, food and textile industry, as reported by Venâncio et al. [13], may have a big impact in the development of two-phase systems for large-scale purification.

The behaviour of an ATPS based on a crude hydroxypropyl starch is studied and compared with the behaviour of a reference system (Reppal PESPEG). Both systems were tested for their ability to purify an enzyme, alcohol dehydrogenase, from a protein extract of Saccharomyces cerevisiae.

\section{Experimental}

\subsection{Chemicals}

Poly(ethylene glycol) (PEG 8000), average molecular mass of $(7-9) \times 10^{3} \mathrm{Da}$, was purchased from Sigma Chemical Co. (St. Louis, MO, USA). Reppal PES 100 (Rep) was obtained from Reppe AB (Vaxjo, Sweden). Crude hydroxypropyl starch (HPS) was a generous gift from Sarcol (Porto, Portugal). Levafix Marine blue E-BNA dye was a generous gift from Bayer Portugal SA (Porto, Portugal). All other chemicals were analytical grade and water was distilled and passed through a mixed ion exchanger.

\subsection{Ligand-PEG synthesis}

The preparation of the conjugate dye/PEG was performed according to Johansson and Joelsson [20].

\subsection{Yeast extract}

Yeast extract was obtained after sonication, with a vibracell sonicator (Sonics and Materials, Danbury, CT, USA), of commercially available baker's yeast. Sonicated cells were centrifuged for $30 \mathrm{~min}$ at $15000 \mathrm{~g}$ and the supernatant collected for partition experiments.

\subsection{Two-phase systems}

The systems were prepared from stock solutions of polymers in water, $40 \%(\mathrm{w} / \mathrm{w})$ Rep, $25 \%(\mathrm{w} / \mathrm{w})$ HPS and $50 \%(w / w)$ PEG 8000 . For system preparation, polymer solutions were weighed out and mixed with water, buffer and yeast extract. System $\mathrm{pH}$ was varied between 5.0 (citric acid- $\mathrm{Na}_{2} \mathrm{HPO}_{4}$ buffer) and 6.0 (phosphate buffer). In all experiments buffer concentration was $10 \mathrm{mM}$ and temperature was $4^{\circ} \mathrm{C}$.

\subsection{Protein and enzyme assays}

Protein was assayed according to Bradford [21], using BSA as standard. ADH ( $\mathrm{p} /=5.4)$ activity was measured according to Racker [22]. One unit (1 U) $\mathrm{ADH}$ activity was defined as the amount of enzyme that produces an increase in absorbance at $340 \mathrm{~nm}$ of 0.001 per minute, at $\mathrm{pH} 8.5$ and $30^{\circ} \mathrm{C}$. Partition coefficient, $K$, was defined as the ratio between upper and bottom phase concentration or activity. ADH recovery in the upper phase, $R_{\mathrm{ADH}, \mathrm{UP}}$, was defined as the ratio between the enzyme activity in the upper phase and the enzyme activity loaded to the system. Protein and ADH recovery in the system, $R_{\text {prot }}$ and $R_{\mathrm{ADH}}$, was defined as the ratio between the amount of protein or ADH founded in both phases and the protein or ADH loaded to the system. Purification, $P$, was defined as follows:

$P=\frac{U_{\mathrm{ADH}, \mathrm{UP}} C_{\mathrm{prot}, \mathrm{UP}}}{U_{\mathrm{ADH}, \mathrm{I}} C_{\mathrm{prot}, \mathrm{I}}}$ 
Table 1

System composition and volume ratio for tested ATPS

\begin{tabular}{lll}
\hline System & Composition & Volume ratio \\
\hline A & 13.5\% Rep-4.5\% PEG 8000 & 1.13 \\
B & $15 \%$ Rep-5\% PEG 8000 & 1.13 \\
C & $8.8 \%$ HPS-3.5\% PEG 8000 & 1.27 \\
D & $9.6 \%$ HPS-3.8\% PEG 8000 & 1.22 \\
\hline
\end{tabular}

where $U_{\mathrm{ADH} . \mathrm{UP}}$ and $U_{\mathrm{ADH}, \mathrm{I}}$ represent the upper phase $\mathrm{ADH}$ activity $(\mathrm{U} / \mathrm{ml})$ and the $\mathrm{ADH}$ activity $(\mathrm{U} / \mathrm{ml})$ loaded to the system, respectively, and $C_{\mathrm{prot}, \mathrm{UP}}$ and $C_{\text {prot, }}$ represent the upper phase protein concentration and the protein concentration loaded to the system, respectively.

\section{Results and discussion}

\subsection{System composition}

The behaviour of several two-phase systems was compared with respect to their ability to purify an enzyme from a crude yeast extract. Polymer compositions of tested systems are shown in Table 1. It can be seen that no significant differences occur in the amount of polymers (either Rep or HPS) needed to form the two-phase system. Rheological behaviour of HPS-PEG systems was analyzed (Table 2) and, as predicted and already reported [13], higher viscosity values were found on the lower phase of this system when comparing with Rep-PEG values (lower phase viscosity close to $100 \mathrm{mPa} s$ [14]). A more detailed rheological study of HPS-PEG systems can be found in previous work [13].

Table 2

Rheological properties (shear rate, $\tau$; viscosity, $\mu$; and density, $\rho$ ) of systems $\mathrm{C}$ and $\mathrm{D}$ at $4^{\circ} \mathrm{C}$

\begin{tabular}{|c|c|c|c|c|c|}
\hline \multirow[t]{2}{*}{ System } & \multicolumn{2}{|c|}{ Upper phase } & \multicolumn{3}{|c|}{ Lower phase } \\
\hline & $\rho\left(\mathrm{kg} / \mathrm{m}^{3}\right)$ & $\mu(\mathrm{mPa} s)$ & $\rho\left(\mathrm{kg} / \mathrm{m}^{3}\right)$ & $\tau\left(s^{-1}\right)$ & $\mu(\mathrm{mPa} s)$ \\
\hline \multirow[t]{2}{*}{ C } & 1022 & 11 & 1088 & 10.2 & 195 \\
\hline & & & & 20.4 & 183 \\
\hline \multirow[t]{2}{*}{ D } & 1020 & 10 & 1107 & 10.2 & 298 \\
\hline & & & & 20.4 & 279 \\
\hline
\end{tabular}

\subsection{ADH partition}

The behaviour of selected two-phase systems was compared with respect to their ability to purify an enzyme, $\mathrm{ADH}$, from a crude extract of $S$. cerevisiae. Partition data for $\mathrm{ADH}$ and total protein at two $\mathrm{pH}$ values $-\mathrm{pH} 5.0$ (below ADH $\mathrm{p} I$ ) and 6.0 (above ADH $\mathrm{pl}$ ) - are represented in Table 3 and Table 4.

The presented values reveal some resemblance between the two types of systems. Either in the Rep-PEG system or the HPS-PEG system the following observations can be made:

1. an increase in $\mathrm{pH}$ increases total protein and $\mathrm{ADH}$ partition coefficients;

2. total protein recovery $\left(R_{\mathrm{prot}}\right)$ is higher for higher $\mathrm{pH}$. This results in a decrease in the purification factor $(P)$ for $\mathrm{ADH}$;

3. the ligand plays an important role in $\mathrm{ADH}$ partition

4. and an increase in the ligand concentration increases the $\Delta \log K_{\mathrm{ADH}}$ value.

However, there are differences between these two systems that must be considered and that are extremely important for its application in protein purification. The Rep-PEG system exhibits higher protein partition coefficients than $\mathrm{ADH}$ partition coefficients, while HPS-PEG systems have higher $\mathrm{ADH}$ partition values. This difference is mainly due to the partition behaviour of $\mathrm{ADH}$, which is much higher in the HPS-PEG system. This last observation explains the higher purification factors $(P)$ obtained for the crude polymer system. It is also observed that Rep-PEG systems present higher recovery of ADH than HPS-PEG systems. On the other hand, the effect of the ligand is higher in the HPS-PEG system (Table 5). This is an interesting result, since it indicates that there is no interference of possible impurities of the crude polymer on affinity partition.

Concerning the ligand efficiency it must be pointed out that saturation was not reached; a linear relationship (Table 5) is evident between $\Delta \log K_{\mathrm{ADH}}$ and ligand concentration for either Rep-PEG or HPS-PEG systems. Affinity partition experiments performed by other authors [23] with the same enzyme and other ligands in dextran-PEG systems 

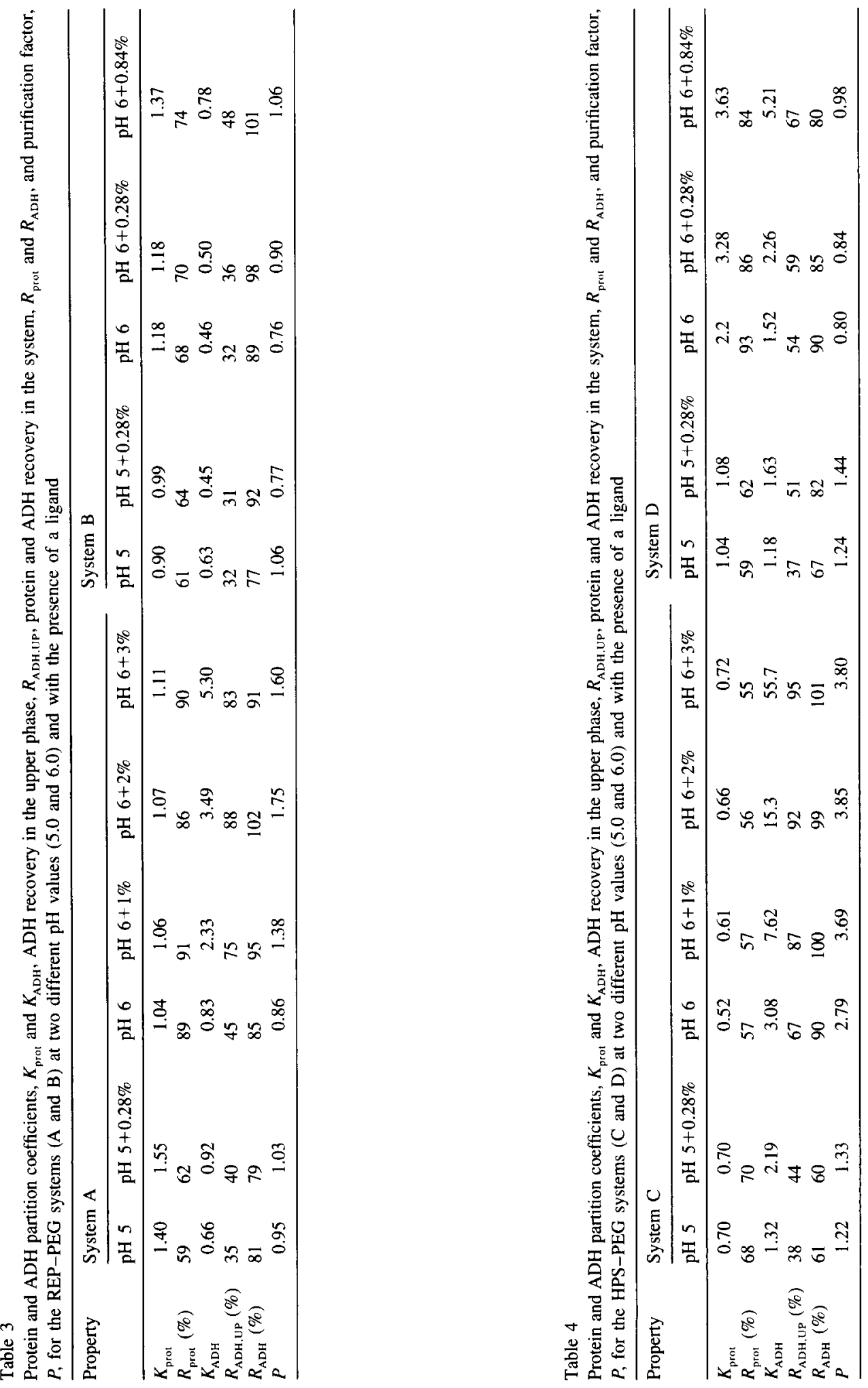
Table 5

Specificity of the ligand to total protein and enzyme, measured as $\Delta \log K$, in systems composed of Reppal PES (A and B) and HPS (C and D)

\begin{tabular}{lllll}
\hline System & $\mathrm{pH}$ & Ligand $^{\mathrm{a}}(\%)$ & $\Delta \log K_{\mathrm{prot}}$ & $\Delta \log K_{\mathrm{ADH}}$ \\
\hline $\mathrm{A}$ & 5.0 & 0.28 & 0.04 & 0.14 \\
& 6.0 & 1.0 & 0.00 & 0.45 \\
& 6.0 & 2.0 & 0.01 & 0.62 \\
& 6.0 & 3.0 & 0.03 & 0.81 \\
$\mathrm{~B}$ & 5.0 & 0.28 & 0.04 & $(-)$ \\
& 6.0 & 0.28 & 0.00 & 0.06 \\
& 6.0 & 0.84 & 0.06 & 0.29 \\
$\mathrm{C}$ & 5.0 & 0.28 & 0.00 & 0.22 \\
& 6.0 & 1.0 & 0.07 & 0.39 \\
& 6.0 & 2.0 & 0.10 & 0.70 \\
& 6.0 & 3.0 & 0.14 & 1.26 \\
$\mathrm{D}$ & 5.0 & 0.28 & 0.00 & 0.14 \\
& 6.0 & 0.28 & 0.18 & 0.14 \\
& 6.0 & 0.84 & 0.21 & 0.53 \\
\hline
\end{tabular}

${ }^{a}$ Measured as percentage of PEG-dye complex per total PEG in the system.

show higher $\Delta \log K_{\mathrm{ADH}}$ values with less ligand, which indicates that it is a less effective ligand for this enzyme. Higher values of ligand concentration were not employed because of an interference with the ADH measuring method.

\section{Conclusions}

From the experiments described in this paper it can be concluded that the use of crude polymers in two-phase partition can and must be considered for large-scale application of ATPS.

Purified fraction of polymers, such as dextran or Reppal PES, can be replaced with crude polymers, such as HPS, without great losses in performance or applicability. As in other systems, environmental conditions, such as $\mathrm{pH}$ and temperature, or the addition of a third compound, can be manipulated in other to achieve a better separation.

Another advantage of the use of crude polymers in ATPS is the cost. As previously reported [13], the replacement of dextran and Reppal PES by this type of polymer can reduce the cost of a two-phase system by factors of 32 and 8 , respectively. Consid- ering the fact that in a large-scale application of a dextran-PEG system, polymer cost can account for as much as $75 \%$ of total production cost [11], the large impact of the use of crude polymers in largescale applications can be foreseen.

\section{Acknowledgments}

A. Venâncio was supported by a JNICT (Junta Nacional de Investigação Científica e Tecnológica) grant.

\section{References}

[1] P.- $\AA$. Albertsson, G. Johansson and F. Tjerneld, in J.A. Asenjo (Editor), Separation Processes in Biotechnology, Marcel Dekker, New York Basel, 1990, Ch. 10, p. 287.

[2] A. Veide, A.-L. Smeds and S.-O. Enfors, Biotechnol. Bioeng., 25 (1983) 1789.

[3] W.-U. Yang, C.-D. Lin, I.-M. Chung and C.-J. Lee, Biotechnol. Bioeng., 43 (1994) 439.

[4] D. Guoqiang, R. Kaul and B. Mattiasson, J. Chromatogr. A, 668 (1994) 145.

[5] S.D. Plunkett and F.H. Arnold, Biotechnol. Techniques, 4 (1990) 45.

[6] E. Andersson and B. Hahn-Hägerdal, Enzyme Microb. Technol., 12 (1990) 242.

[7] K.H. Kroner, H. Hustedt and M.-R. Kula, Process Biochem., 19 (1984) 170.

[8] J.A. Asenjo, R.E. Turner, S.L. Mistry and A. Kaul, J. Chromatogr. A, 668 (1994) 129.

[9] M.-R. Kula, in Derek Fisher and Ian A. Sutherland (Editors), Separation Using Aqueous Two-Phase Systems, Plenum Press, New York, 1989, Ch. 7, p. 295.

[10] S. Sturesson, F. Tjerneld and G. Johansson, Appl. Biochem. Biotechnol., 26 (1990) 281.

[11] R. Datar, Process Biochem., 21 (1986) 19.

[12] K.H. Kroner, H. Hustedt and M.-R. Kula, Biotechnol. Bioeng., 24 (1982) 1015.

[13] A. Venâncio, J.A. Teixeira and M. Mota, Biotechnol, Progr., 9 (1993) 635.

[14] F. Tjerneld, S. Berner, A. Cajarville and G. Johansson, Enzyme Microb. Technol., 8 (1986) 417.

[15] F. Tjerneld, in Derek Fisher and Ian A. Sutherland (Editors), Separation Using Aqueous Two-Phase Systems, Plenum Press, New York, 1989, Ch. 10, p. 429.

[16] D.C. Szlag and K.A. Giuliano, Biotechnol. Techniques, 2 (1988) 277.

[17] D.R. Skuse, R. Norris-Jones, M. Yalpani and D.E. Brooks, Enzyme Microb. Technol., 14 (1992) 785. 
[18] U. Dissing and B. Mattiasson, Biotechnol. Appl. Biochem., 17 (1993) 15.

[19] A.S. Medin and J.-C. Janson, Carbohydr. Polymers, 22 (1993) 127

[20] G. Johansson and M. Joelsson, Biotechnol. Bioeng., 27 (1985) 62.
[21] M.M. Bradford, Anal. Biochem., 72 (1976) 248.

[22] E. Racker, Methods Enzymol., 1 (1955) 500.

[2.3] J.H.J. Pesliaskas, V.D. Zutautas and A.A. Glemza, Chromatographia, 26 (1988) 85. 